\title{
Fixation increases sequestration
}

Biological nitrogen fixation (BNF) supplies the majority of nitrogen to natural terrestrial systems. The amount of nitrogen fixed and thus available for biological activity impacts primary productivity, biogeochemical cycling and carbon sequestration in vegetation and soil. The impact of climate change, increased atmospheric $\mathrm{CO}_{2}$ and increased anthropogenic nitrogen deposition are expected to influence BNF in the 21st century. For example, increasing temperatures in relatively cold climates can stimulate BNF, and increased $\mathrm{CO}_{2}$ can promote primary production, requiring more bioavailable nitrogen. However, the

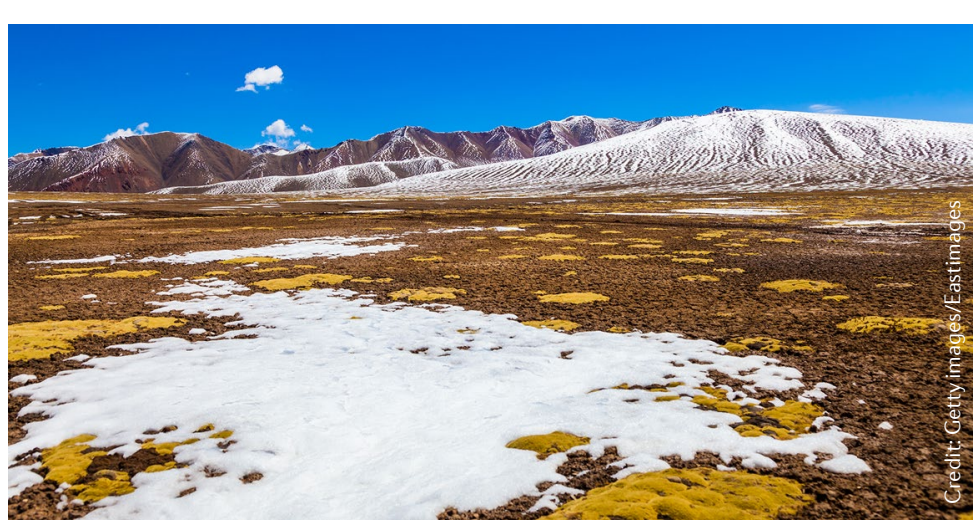

magnitude of changes in BNF and the resulting impacts on carbon cycling and sequestration are debated.

Jing Peng of the Institute of Atmospheric Physics, Chinese Academy of Science, China and colleagues modelled the response of BNF and related carbon sequestration impacts to global change factors from 1901 to 2100. Assuming a 'business-as-usual' scenario (RCP 8.5), by 2100 , the global BNF rate is estimated to increase by up to $56 \%$ relative to current levels. Most of this change is driven by increases in atmospheric $\mathrm{CO}_{2}$ and temperature, with the latter playing a large role in the high

latitudes especially. The higher rates of BNF are expected to result in up to $16 \%$ (or $68 \mathrm{Pg}$ ) more carbon sequestered on land by 2100 , when compared to 1901 levels. Notably, these estimates are up to $35 \%$ more than those projected by CMIP5 models, which did not consider the carbon-nitrogen interactions used in this study.

Global changes can have cascading effects, as seen here with BNF and terrestrial carbon sequestration. Not considered, though, was the impact of land use change, variations in nitrogen-rich fertilizer usage, and feedbacks between nitrogen and phosphorus; all of these factors can influence the rate and spatial distribution of BNF. Additionally, more field measurements of BNF, especially in the high latitudes (where the changes in BNF are predicted to be prominent) are needed to ground-truth model results.

Laura Zinke

ORIGINAL ARTICLE Peng, J. et al. Global carbon sequestration is highly sensitive to model-based formulations of nitrogen fixation. Global Biogeochem. Cycles https://doi.org/10.1029/ 2019GB006296 (2019) 